\title{
Comparative Study on the Incidence of White Mold (Sclerotinia Sclerotiorum) on Stored Carrot within Two Markets in the Tamale Metropolis of Northern Region
}

\author{
Elias Nortaa Kunedeb Sowley, Frederick Kankam* and Deborah Akpene Kundo \\ ${ }^{1}$ Department of Agronomy, Faculty of Agriculture, University for Development Studies \\ Tamale, Ghana. \\ ${ }^{*}$ Corresponding author's email: fkankam [AT] uds.edu.gh
}

\begin{abstract}
Sclerotinia sclerotiorum is predominant among other fungi species responsible for rot of several crops on the field and in storage. It results in an important economic loss in stored carrot roots and other economic important crops and vegetables. This makes Sclerotinia sclerotiorum a polyphagous fungus. S. sclerotiorum is a cosmopolitan fungus that affects most crops and vegetables in the tropics and temperate regions. The study was conducted to determine the incidence of $S$. sclerotiorum in stored carrots within the two major markets (Tamale central and Aboabo) of the Tamale Metropolis of the Northern region of Ghana. Fifteen (15) carrot samples each were collected from the two markets and from different storage containers (storage in sack, basket and pan). Four different fungi species were isolated from the carrot samples. These were Sclerotinia sclerotiorum, Botrytis cinerea, Aspergillus niger and Aspergillus clavatus. The total incidence of fungi species among the two markets showed significant difference $(P<0.05)$. S. sclerotiorum recorded varied occurrences across the two markets with the highest incidence recorded in the Tamale Central market (44.4\%). S. sclerotiorum was predominant in carrots from the markets than the other fungi. The incidence of S. sclerotiorum varied in different storage containers. Storage using sack recorded the highest incidence (70.0\%) of S. sclerotiorum followed by storage using pan (32.7\%) with the lowest incidence recorded in storage using basket (24.0\%). However, S. sclerotiorum was found to be associated with carrots from the two markets studied. Hence appropriate storage containers such as storage using baskets are recommended as a way of combating the high incidences of $S$. sclerotiorum.
\end{abstract}

Keywords-Carrot, white mold, Tamale central, Aboabo

\section{INTRODUCTION}

Carrot (Daucus carota L.) is a popular exotic vegetable grown throughout the world [1]. It is grown for its fresh roots and it is either eaten fresh or cooked [2]. Carrot is a biennial crop which is usually cultivated as an annual crop in the tropics [3]. It is an important vegetable which is ranked third among the succulent vegetables in the world production [4, 5]. The annual world production of carrot has increased by $133 \%$ during the past 3 decades amounting to 19.4 million metric tons in 2000 [6]. Presently, carrot is a commercially important crop that represents $1.4 \%$ of the total world root, tuber and other vegetable production [6]. Carrots are produced in at least 108 countries throughout the six continents [6].

One of the prevalent storage diseases of carrot is the sclerotinia rot, also known as cottony rot or white mold is caused by the Sclerotinia sclerotiorum fungi [7]. The inoculum responsible for this disease of carrots originate primarily from infected and infested roots from the field [7]. According to Bolland and Hall [8], the fungus Sclerotinia sclerotiorum is a polyphagous species that affects over 400 plant species around the world. Host plants infested by this fungus include many vegetable crops such as; carrot, tomato, green pepper, lettuce and cabbage [9].

Despite the importance of carrot, it is faced with several challenges from cultivation through to storage. The continuous availability of quality carrot beyond the normal harvest season remains a primary challenge to producers globally and also storage methods between harvest and marketing vary among regions [10]. According to Hasen et al. [11], serious losses have been recorded in the United States during storage of carrot due to white mold. Ghana is not exempted from this problem in Africa because optimum temperature for disease development ranges from $15-21^{\circ} \mathrm{C}$ [12].

Proper storage method is one of the factors to effectively reduce or suppress infection by Sclerotinia sclerotiorum. Inappropriate storage conditions allow for the easy development and spread of the fungus. Severe infections result in rotting and thereby producing bad smells. Other control measures including biological and chemical means together with proper storage temperature are essential for minimizing moisture loss and reducing microbial activities on stored carrot. 
The goal of the present study, therefore, was to determine the incidence of white mold fungi (S. sclerotiorum) and storage containers on stored carrots in the Tamale Central and Aboabo markets.

\section{MATERIALS AND METHODS}

\subsection{Study site}

The study was conducted in 2 markets (Tamale central market and Aboabo) within the Tamale metropolis in the Northern region of Ghana. Tamale Metropolis occupies approximately $922 \mathrm{~km}^{2}$ which is about $13 \%$ of the total land area of the Northern region. It shares common boundaries with Tolon-Kumbungu, East and West Gonja Districts [13]. The work was conducted at the Tissue culture laboratory of the University for Development Studies, Nyankpala Campus. The Tamale metropolis is located at latitude 9o 25 North and longitude 0o 51 West and has an elevation of approximately $173 \mathrm{~m}$ (568 feet). It experiences a single rainy season starting from late April with little rainfall, rising to its peak in JulyAugust and declining sharply to a complete halt in October-November. Daily temperatures vary from season to season. There is mostly high humidity and heavy thunder storms with slight sunshine in the wet season as compared to the dry season which is characterized by dry harmattan winds from November to February and high sunshine from March to May. This climatic feature offers a unique opportunity for the preservation industries in that it could use the sunshine as a natural preservative. The mean annual rainfall ranges from $950 \mathrm{~mm}-1200 \mathrm{~mm}$ [14]. It is within the Guinea Savannah zone with tall grasses interspersed with drought-resistant trees such as acacia (Acacia longifolia), mango (Magnifera indica), baobab (Adansonia digitata), shea (Vitellaria paradoxa), dawadawa (Parkia biglobosa), mahogany (Khaya senegalensis) and neem (Azadirachta indica). Major tree species include the shea, dawadawa, and mango, which are economic trees and form an integral part of livelihood of the natives.

\subsection{Carrot sample collection}

Fifteen carrots roots were randomly collected each from the Tamale Central and the Aboabo markets. The obtained samples were packed into paper bags to prevent further contamination and then transported to the laboratory.

\subsection{Experimental Design}

Completely Randomised Design (CRD) was used in the experiment.

\subsection{Sterilisation of equipment}

Before the isolation and identification of fungi, several laboratory operations were carried out in order to avoid all forms of contaminations. Such operations included sterilization of all glasswares by autoclaving and using $95 \%$ alcohol for disinfection. All chemically treated glassware was rinsed thoroughly in three changes of sterile water.

Sodium hypochlorite was used as a surface sterilant to treat surface of infested tissue to reduce surface contaminants that would interfere with isolation.

\subsection{Media Preparation}

The preparation of the media was based on the directions given by the manufacturer (Oxoid, UK). Thirty-nine (39) grams of Potato Dextrose Agar (PDA) powder was dissolved in 1litre (L) of distilled water in a conical flask. The opening of the flask was covered with aluminium foil to prevent contamination, condensation and moisture loss. A magnetic stirrer was used to stir the mixture while heating on the heating mantle to obtain a uniform mixture. The mixture was then autoclaved at $121^{\circ} \mathrm{C}$ at 1 bar pressure for 15 minutes. Twenty (20) ml each of the melted PDA was poured into sterilized Petri dishes in a controlled environment (lamina flow hood) and allowed to solidify.

\subsubsection{Isolation}

The carrot samples were sliced into pieces and surface sterilized in 3\% Sodium hypochlorite (NaOCl) solution in order to prevent the fungi within from being killed whiles reducing surface contaminants at the same time. Sliced carrots were rinsed in 3 changes of distilled water and left to dry on sterilized filter papers. For each carrot sample, five slices were plated at equidistant on PDA contained in a Petri dish. Each sample was replicated 3 times. The plated carrot slices were incubated at room temperature of $25^{\circ} \mathrm{C}$ for 5 days. Mixed cultures of various species of fungi were obtained from the plated carrot slices. Each distinct culture constituting the mixed culture was sub-cultured unto fresh PDA plates. The sub-culturing of each fungus continued until the various pure cultures were obtained.

\subsubsection{Identification of Sclerotinia sclerotiorum}

Sclerotinia sclerotiorum was identified by a white cottony dense mat of mycelia on surface of host crop. Within the fluffy white mass is a dense white body which becomes black and hard as they mature, known as sclerotia. It produces large smooth rounded sclerotia $(2-10 \mathrm{~mm}$ in diameter) [15]. 


\subsubsection{Identification of Botrytis cinerea}

Botrytis cinerea is also known as gray mold fungi. It is a filamentous fungal pathogen that causes loss on carrot during growth and storage [16]. Isolation and identification of the gray mold was based on the abundant blackish gray mycelia and conidia on the in plates of carrot [17].

\subsubsection{Identification of Aspergillus niger and Aspergillus clavatus}

The most common method used for identification of Aspergillus isolates is based on the colony characteristics and morphological characteristics. They are easily distinguished based on the spore bearing structures or conidiophores having an erect hyphal with a swollen vesicle which bears the conidia [18].

\subsection{Determination of incidence of white mold}

The incidence of white mold on carrot was determined using a count method described by Singh et al. [19]. The percentage incidence of white mold and other associated fungi from the total count obtained from the markets was calculated using the formula;

Percentage occurrence $=($ number of times a fungus was encountered $) /($ total fungal isolations $) \times 100$

The incidence of fungi based on the various storage containers used by vendors was determined by calculating the average percentage incidence of each of the fungi incidence based on the various storage containers used in the two markets. This is given by the formula below:

$\%$ occurrence in storage container $=($ sum of a given fungi $\%$ incidence based on a storage method) $/$ (number of incidences of a given fungi in the storage method)

\subsection{Pathogenicity test using fungi isolates}

Healthy carrots were sliced into pieces and surface sterilised in $3 \%$ Sodium Hypochlorite solution. Pure isolates of white mold fungi were inoculated on sliced carrots on PDA media and the plates were incubated at room temperature $\left(25^{\circ} \mathrm{C}\right)$ for two weeks. Inoculation was done by using an inoculation loop or pin to pick a loop of the pure isolates of white mold fungi onto the healthy carrot slices. The same procedure was used in the inoculation of the other fungi (Botrytis cinerea, Aspergillus niger and Aspergillus clavatus). Three replications were prepared for each treatment (fungus). The control consisted of sterilised $3 \mathrm{~mm}$ PDA disc placed in holes made in healthy bulbs. Observation for symptoms development was made and the degree of pathogenicity of each fungus determined by measuring the extent of the rot $(\mathrm{mm})$ on the inoculated slides with a ruler.

\subsection{Statistical Analysis}

Data was subjected to ANOVA (Analysis of Variance) using generalized linear model (GLM) in Genstat (edition 4) and the means were separated at 5\%. Results from analysis were presented in graph

\section{RESULTS}

\subsection{Percentage occurrence of fungal species on stored carrots in the Tamale Central and Aboabo markets}

Four different species of fungi were isolated from all thirty samples collected from the two markets within the Tamale metropolis. These were Sclerotinia sclerotiorum (White mold), Botrytis cinerea (Gray mold), Aspergillus niger and Aspergillus clavatus. The Sclerotinia sclerotiorum percentage occurrences recorded for the Tamale Central (44.4\%) and Aboabo $(40.0 \%)$ markets were significantly higher $(P<0.05)$ than that of each of Botrytis cinerea. Aspergillus niger and Aspergillus clavatus (Figure 1). However, there was no significant difference $(P>0.05)$ between the percentage occurrence of S. sclerotiorum recorded for the Tamale Central and Aboabo markets (Figure 1). The percentage occurrence for Botrytis cinerea (23.6\%) recorded for each of the Tamale Central and Aboabo markets were significantly higher $(P<0.05)$ than what was observed for each of Aspergillus niger and Aspergillus clavatus (Figure 1). The occurrence of Aspergillus niger in the Tamale Central and the Aboabo markets were 8.6 and $11.9 \%$ respectively which were also significantly higher $(P<0.05)$ than the incidence of Aspergillus clavatus (Figure 1). However, Aspergillus clavatus with an incidence of $3.11 \%$ was only recorded for Aboabo but not the Tamale Central market (Figure 1). 

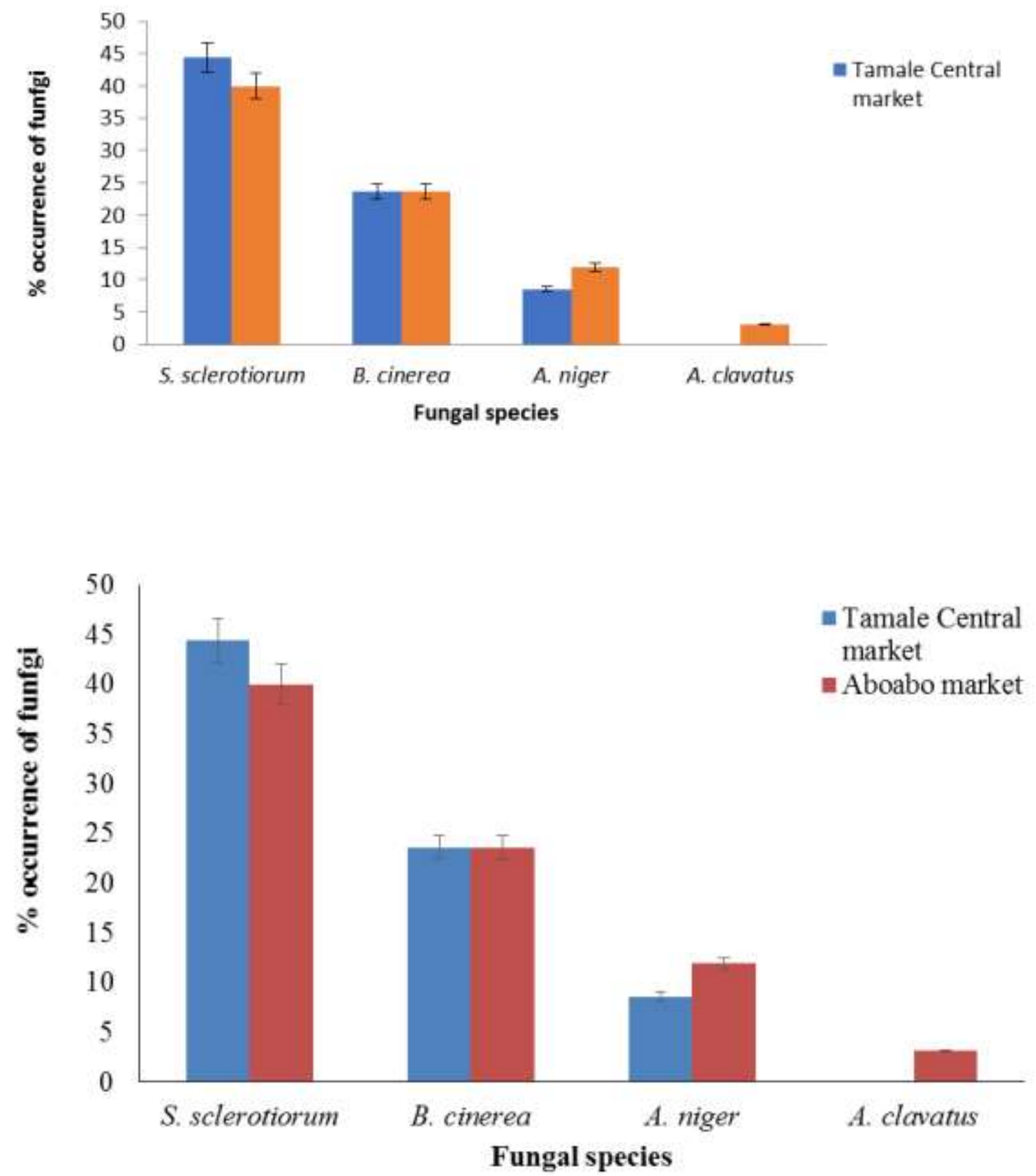

Figure 1: Percentage occurrence of fungal species on stored carrot in the Tamale Central and Aboabo markets

\subsection{Percentage occurrence of fungal species of carrots stored in different storage containers.}

In the Tamale Central and the Aboabo markets, carrots were stored in sacks, baskets or pans. The Percentage occurrences of fungal species of carrots stored in different storage containers have been illustrated in Figure 2. Sclerotinia sclerotiorum recorded the highest percentage occurrence in storage by sack $(70.0 \%)$ followed by storage by pan $(32.7 \%)$ and basket storage recorded the least incidence $(24.0 \%)$. Botrytis cinerea recorded highest percentage occurrence in storage by basket $(29.3 \%)$ followed by pan $(22.0 \%)$ and then storage in sacks recorded the least incidence (19.3\%). Aspergillus niger recorded highest percentage incidence in storage in pans $(12.8 \%)$ followed by basket storage $(10.7 \%)$ and sack storage recorded the least $(7.3 \%)$. Aspergillus clavatus recorded percentage occurrence of $4.7 \%$ in basket storage method with no incidence in the sack and pan storage method. Generally, there were significant difference $(P<0.05)$ among the incidence of the various fungi $(S$. sclerotiorum, B. cinerea, A. niger and A. clavatus) recorded on the carrot in relation to the storage containers. 


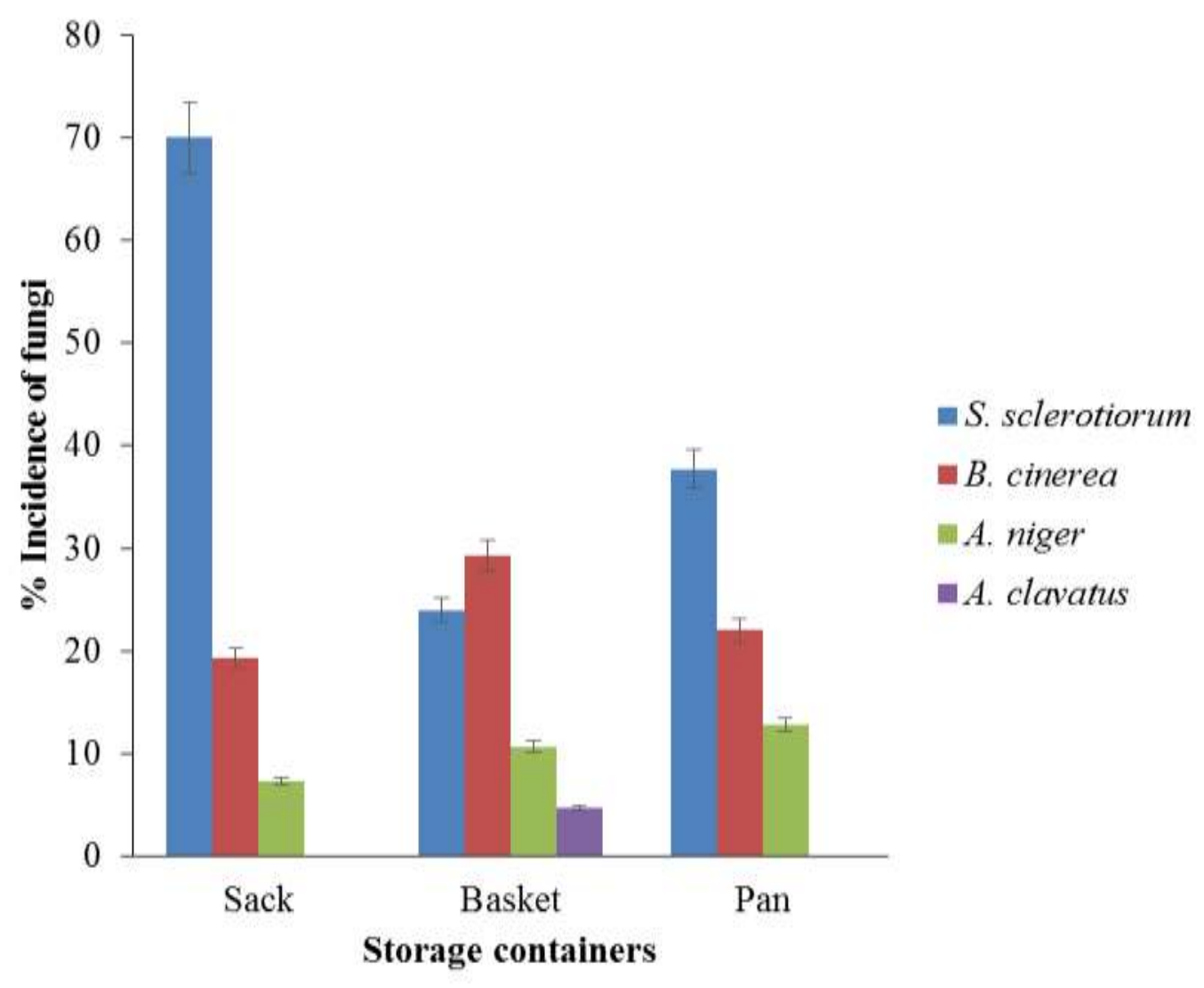

Figure 2: Percentage occurrence of fungal species base on storage method

\subsection{Percentage occurrence of Sclerotinia. sclerotiorum based on storage containers between markets}

The results obtained for the percentage occurrence of Sclerotinia sclerotiorum based on storage containers between the Tamale Central and Aboabo markets are presented in Figure 5. The percentage occurrence of S. sclerotiorum in the sack stored carrots for each of the Tamale Central (73.3\%) and the Aboabo (66.7\%) markets where significantly higher $(P<0.05)$ than what were recorded for the basket and pan storage containers for the two markets. However, there was no significant difference between the percentage occurrences of $S$. sclerotiorum for the sack storage containers in the Tamale Central and the Aboabo markets. The percentage occurrence of S. sclerotiorum for the pan storage in the Tamale Central $(33.3 \%)$ and Aboabo $(32.0 \%)$ markets where significantly higher $(P<0.05)$ than that of the basket method for the two markets. There was no significant difference $(P<0.05)$ between the $S$. sclerotiorum percentage occurrence on the pan storage carrot for the Tamale Central and Aboabo markets. The basket stored carrot in the Tamale Central market $(26.7 \%)$ recorded a significantly higher $(P<0.05)$ S. sclerotiorum percentage occurrence than that of the Aboabo market $(21.3 \%)$. 


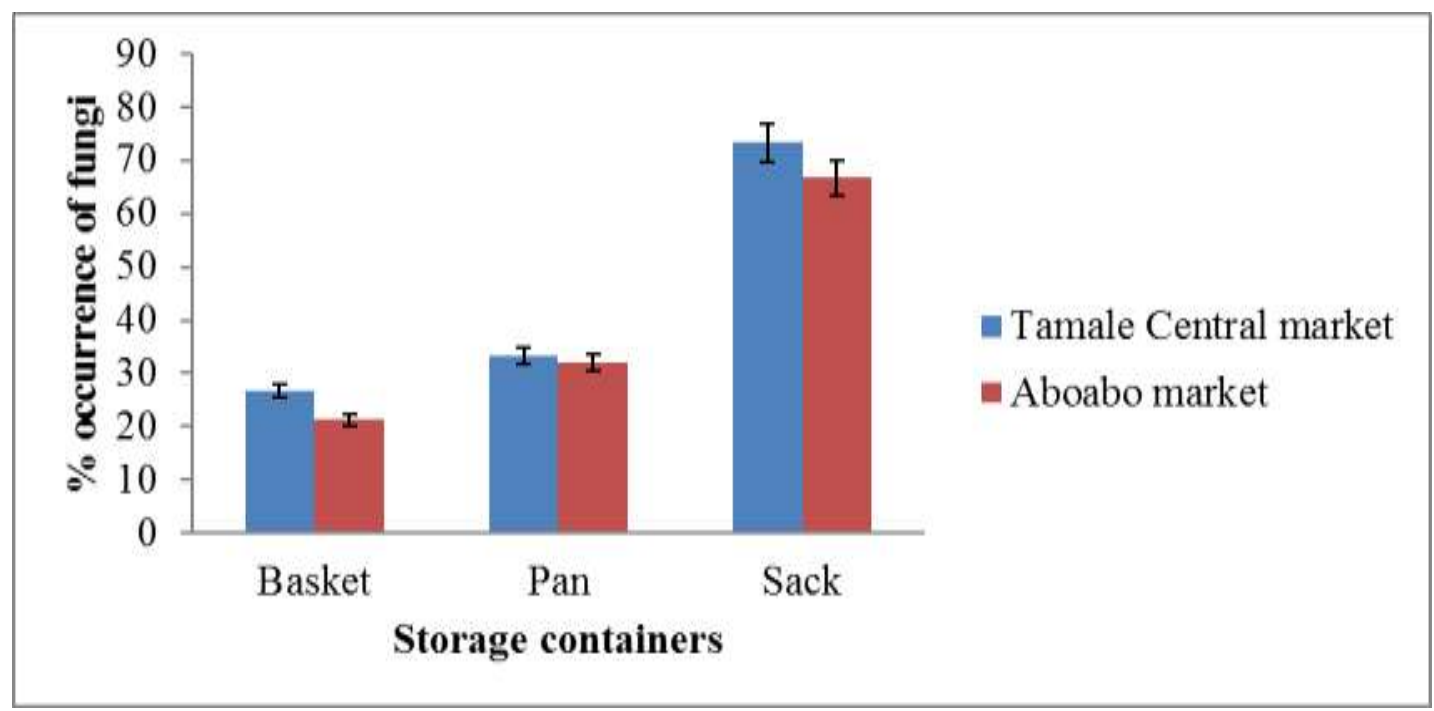

Figure 3: Percentage occurrence of S. sclerotiorum based on storage methods from the various market

\section{DISCUSSION}

Generally, Sclerotinia sclerotiorum was present in carrot samples from the two markets (Tamale Central and Aboabo) within the Tamale Metropolis. This fungus recorded the highest incidence amongst other fungi species in all the samples collected from these markets. This affirmed the reports of Mendes et al. [9] and Reis and Lopes [20] that White mold is a very serious problem in vegetable crops such as carrot, potato, tomato, green pepper, eggplant, lettuce and some brassicaceous species. It also agrees with the report by Shika and Doug [21] which indicated that most postharvest losses in carrots are due to Scleotinia rot, Botrytis rot, Bacterial soft rot and Sour rot. Of these Sclerotinia sclerotiorum is the most prevalent.

The considerably high incidences of Sclerotinia sclerotiorum in carrot from all the sources could be mainly attributed to the wide range of temperatures in the study areas. This affirmed the report by Lobo Júnior et al. [12] that the optimum temperature for disease development ranges from $15^{\circ} \mathrm{C}$ to $21^{\circ} \mathrm{C}$ the sclerotium needs high air humidity and free water on plant to infect its hosts.

Generally, there was significant difference in the incidences of Sclerotinia sclerotiorum recorded in carrot samples from the different storage containers (sack, basket and pan) in the study areas with storage by sack recording the highest incidence. It is likely that the different storage methods provided different storage conditions that influenced the mycelium growth in storage. This could be attributed to the exposure of carrots to conditions which favoured the development of the fungi. This agrees with the report by Fandohan et al. [22] that some storage containers do not safe guard produce from mould infection as well as protection of produce against other contaminants. The high incidence of $S$. sclerotiorum in the sack storage method could be that the sack provided moist and humid conditions that facilitated fungal growth. It confirmed the report by Hell et al. [23] and Udoh et al. [24] who indicated that many farmers nowadays store their produce in sacks, especially polypropylene which are not airtight, with evidence that this method facilitates fungal contamination. It also agrees with the report by Reis and Lopes [20] that White mold becomes a serious problem in wet and cool environments.

\section{CONCLUSION}

Sclerotinia sclerotiorum was found to be associated with carrot samples from the two markets within Tamale metropolis (Tamale central and Aboabo). However, its occurrence varied across the two study areas. Very high incidences were recorded in carrot samples from Tamale central market followed by Aboabo market. Apart from Sclerotinia sclerotiorum, other fungi such as Botrytis cinerea, Aspergillus niger and Aspergillus clavatus were also isolated from the carrot samples. Sclerotinia sclerotiorum causes serious pre-harvest and postharvest losses and it is therefore important to control this fungus to its minimum.

\section{ACKNOWLEDGEMENT}

The authors are thankful to the laboratory technicians and research assistants of the Agronomy Department of the University for Development Studies, for assisting in the data collection. 


\section{REFERENCES}

[1] Norman JC, “Tropical Vegetable Crops”. Arthur Stockwell Ltd., London. pp. 252, 1992.

[2] Sinnadurai S, "Vegetable Production". Asempa Publisher, Box 919 Accra. pp. 208, 1992.

[3] De Lonny, "Effects of Sowing Methods and Phosphorus Application on the Performance of two Alfalfa Cultivars". MSc. Thesis, University of Khartuom, Sudan. 2001.

[4] Yamaguchi. "Effect of Plant Density as well as Nitrogen and Phosphorus fertilizer on Growth, Green pods and Dry seed yield and Quality of Broad bean". Annals of Agricultural Science, Moshtohor, vol 33(1), pp. 371-388, 1983.

[5] Bassett MJ, "Breeding Vegetable Crops", AVI Publishing Company, Inc., Connecticut, pp. 584, 1986.

[6] Anonymous. "2000 FAO Production Yearbook", FAO, Rome, Italy Vol. 54, 2001.

[7] Snowdon AL, "Color Atlas of Post-Harvest Diseases and Disorders of Fruits and Vegetables", Vegetables. Boca Raton, FL. USA CRC, vol. 2, 1992.

[8] Bolland G, Hall R, "Index of Plant Hosts to Sclerotinia sclerotiorum", Canadian Journal of Plant Pathology, vol 16, pp. 93-108, 1994.

[9] Mendes M, Silva VL, Dianese JC, Ferreira M, Santosce N, Gomesneto E, Urbena F, Castro C, "Fungos em Plantas no Brasil”. Brasília: Embrapa Cenargen, pp. 569, 1998.

[10] Lewis B. G, Garrod B. "Post -Harvest Pathology of Fruits and Vegetables". C. Dennis, ed. Academic Press, London. pp.103-24, 1983.

[11] Hansen J, Tobias D, Balbyshev N, Stack R, Lee C, "Effect of preharvest benomyl spray on winter storage of carrots". Phytopathology, vol 91, pp.178. 2001.

[12] Lobo Junior M, Lopes CA, Siliva WLC, "Sclerotinia rot losses in processing tomatoes grown under centre pivot irrigation in central Brazil”. Plant Pathology, vol 49 pp. 51-56, 2000.

[13] Ghana Statistical Service, October, 2014

[14] Regional Metrological Department- Tamale, 2005

[15] Agrios GN, "Plant Pathology 5th edn". Elsevier Academic press, Oxford, UK, pp. 593-599, 2005.

[16] Govrin E, Levine A, "The hypersensitive response facilitates plant infection by the necrotrophic pathogen Botrytis cinereal”. Current Biol., vol 10, pp. 751-757, 2000.

[17] Aktaruzzaman M, Joon YK, Sheng JX, Byung SK, "First Report of Postharvest Gray Mold Rot on Carrot caused by Botrytis cinerea in Korea". Department of Plant Science, Gangneung- Wonju National University, Gangneung, Korea, pp. 210-702, 2014.

[18] Klich MA, "Identification of Common Aspergillus species”. vol 116, pp. 90-70-351-46-3, 2002.

[19] Singh CS, Kapoor A, Wange SS, "The enhancement of root colonization of legumes by vesicular-arbuscular mycorrhizal (VAM) fungi through the inoculation of the legume seed with commercial yeast (Saccharomyces cerevisiae)". Plant and Soil, vol 131, pp.129-133, 1991.

[20] Reis A, lopes CA, "Principais fungos de solo em Hortaliças, Epidemiologia e manejo". Manejo integrado de doenças e pragas, Hortaliças, Viçosa, UFV, pp.189-224, 2007.

[21] Shika A, Doug W, Department of Plant Sciences, University of Saskatchewan, 2001.

[22] Fandohan P, Gnonlonfin B, Hell K, Marasas WF, Wingfield MJ, "Natural occurrence of Fusarium and subsequent fumonisin contamination in preharvest and stored maize in Benin, West Africa". Int J Food Microbiol, vol (2) 99, pp. 173-183, 2005.

[23] Hell K, Cardwell KF, Setamou M, Poehling HM, "The influence of storage practices on aflatoxin contamination in maize in four agro-ecological zones of Benin, West Africa". Journal of Stored Products Research, vol 36, pp. 365382, 2000.

[24] Udoh JM, Cardwell KF, Ikotun T, 'Storage structures and aflatoxin content of maize in five agroecological zones of Nigeria'. Journal of Stored Products Research, vol 36, pp. 187-201, 2000. 